\title{
Geostatistical approach for identification of transmissivity structure at Dulliu area in Taiwan
}

Yu-Pin Lin · Chi-Chun Lee · Yih-Chi Tan

Abstract A thorough understanding of the characteristics of transmissivity makes groundwater deterministic models more accurate. These transmissivity data characteristics occasionally possess a complicated spatial variation over an investigated site. This study presents both geostatistical estimation and conditional simulation methods to generate spatial transmissivity maps. The measured transmissivity data from the Dulliu area in Yun-Lin county, Taiwan, is used as the case study. The spatial transmissivity maps are simulated by using sequential Gaussian simulation (SGS), and estimated by using natural log ordinary kriging and ordinary kriging. Estimation and simulation results indicate that SGS can reproduce the spatial structure of the investigated data. Furthermore, displaying a low spatial variability does not allow the ordinary kriging and natural log kriging estimates to fit the spatial structure and small-scale variation for the investigated data. The maps of kriging estimates are smoother than those of other simulations. A SGS with multiple realizations has significant advantages over ordinary kriging and even natural log kriging techniques at a site with a high variation in investigated data. These results are displayed in geographic information systems (GIS) as basic information for further groundwater study.

Keywords Geostatistical simulation · GIS · Kriging $\cdot$ Spatial variability $\cdot$ Transmissivity

Received: 27 August 1999 - Accepted: 22 February 2000

Y.P. Lin

Department of Landscape Architecture, Chinese Culture University, 55 Hwa-Ken Rd. Yangming Shan, Taipei 111, Taiwan

C.C. Lee · Y.C. Tan (

Department of Agricultural Engineering, and Hydrotech Research Institute, National Taiwan University, Taipei 106, Taiwan

e-mail: yctan@ccms.ntu.edu.tw

Fax: + 8862-2363-9557

\section{Introduction}

Transmissivity is the main basic parameter for hydrogeological properties in groundwater models. This parameter sometimes contains significant levels of uncertainty, including complex (unexplainable) variations in the observed values of measurable attributes over an investigated area. For instance, Freeze (1975) noted that all soil and geological formations contain seemingly random variations in their spatial hydrogeological properties. Therefore, characterizing the spatial distribution of transmissivity for groundwater models is essential. These hydrogeological property variabilities have induced many authors to use statistical procedures to model the spatial structures of interesting geohydrological and physicochemical properties. Examples of such works include Bark and others (1978), Journel and Huijbregts (1978), Delhomme (1979), Smith and Freeze (1979), Chirlin and Dagan (1980), Smith (1981), Clifton and Neuman (1982), Anderson and Shapiro (1983), Hoeksema and Kitanidis (1985), Neuman and others (1987), Rubin (1990), Bjerg and others (1992), Eggleston and others (1996), Fabbri (1997), Christensen (1997), Difederico and Neuman (1997), and Salandin and Fiorotto (1998).

The kriging process yields weighted-average estimates that may fail to preserve the variability of the investigated process. Minimizing the prediction error variance involves smoothing the actual variability (Journel and Huijbergts 1978). The estimated values based on kriging display a lower variation than the actual investigated values. However, estimation techniques are designed to minimize local uncertainties and not to reproduce global patterns (Christakos 1992). Geostatistical simulation can be performed to correct the above deficiency. Simulation generates equally likely sets of values for a variable, which are consistent with the available in situ measurements. This often implies that the simulated values have the same mean and the same variogram as the original data, and may also have to coincide with the original data at the measurement points. Simulation focuses mainly on reproducing the fluctuations in the observations, instead of producing the optimal prediction (Sterk and Stein 1997). On the other hand, the investigated data occasionally possess a skewed, even lognormal, distribution. Therefore, lognormal kriging was developed within geostatistics to account for the frequently skewed distri- 
bution of the investigated data (Roth 1998). This technique transforms the data into a lognormal formation before kriging estimation. Notable works on this technique include Rendu (1979), Journel (1980), Dowd (1982), Rivoirard (1990), Christensen (1997), Fabbri (1997), and Roth (1998).

Conditional simulation attempts not only to generate a set of values that have some specified mean and covariance, but also to reproduce observed data at several locations. Thus, conditional simulations are useful in many instances. For example, such measurements can be used, along with simulated values, to analyze the spatial distribution of the variable in question, assuming that a variable is investigated at several locations. Varljen and Shafer (1991) established a conditional simulation to determine a cap by simulating transmissivity. Eggleston and others (1996) applied conditional simulation and ordinary kriging to reproduce hydraulic conductivity structure and sensitivity under limited amounts of data. Later, Mowrer (1997) applied a sequential Gaussian simulation (SGS) to create maps of potential old-growth forest conditions across a 121-ha first-order subalpine watershed. More recently, Kentwell and others (1999) used SGFS to enhance the prediction accuracy of a grade tonnage curve.

In this study, conditional simulation technique, natural log ordinary kriging and ordinary kriging are applied herein to produce the realizations and maps of transmissivity in a real case study. The descriptive statistics, spatial structure (experimental variogram) and spatial patterns of estimated and simulated results are also discussed. Finally, the estimation and simulation results are also shown in geographic information systems (GIS).

\section{Case study}

The study area is located on the east banks of the middle and upper streams of the Peikang River in Yun-Lin County, Taiwan. The branch streams of the Peikang River, such as the Ta Huko River and Huahsing River, including Huwei, Tuku, Yuangchang, Tounan, Tapei and Kukeng, are also included as illustrated in Fig. 1. The locations of sampling wells are also shown in Fig. 1. The geological conditions of the study area from Dulliu Hill to the Peikang River encompass the Toukoshan formation, terrace deposits and alluvium as presented in Fig. 2. The stream origins carry the material washed away by rainfall at the Liushuang formation of Dulliu Hill and deposit them on the Tainan formation as falling-stone deposits. The Liushuang formation is mainly an inter-layer of mudstone and shale in which most of the accumulated material is muddy. Moreover, a layer containing gravel mixed with soil or a muddy stratum with gravel also appears. Part of the west bank of the Peikang River belongs to the alluvia fan of the Chuo-Shuei River. It has a rather typical alluvia fan stratum structure because the east side gravel layer is rather thick and reduces gradually to the

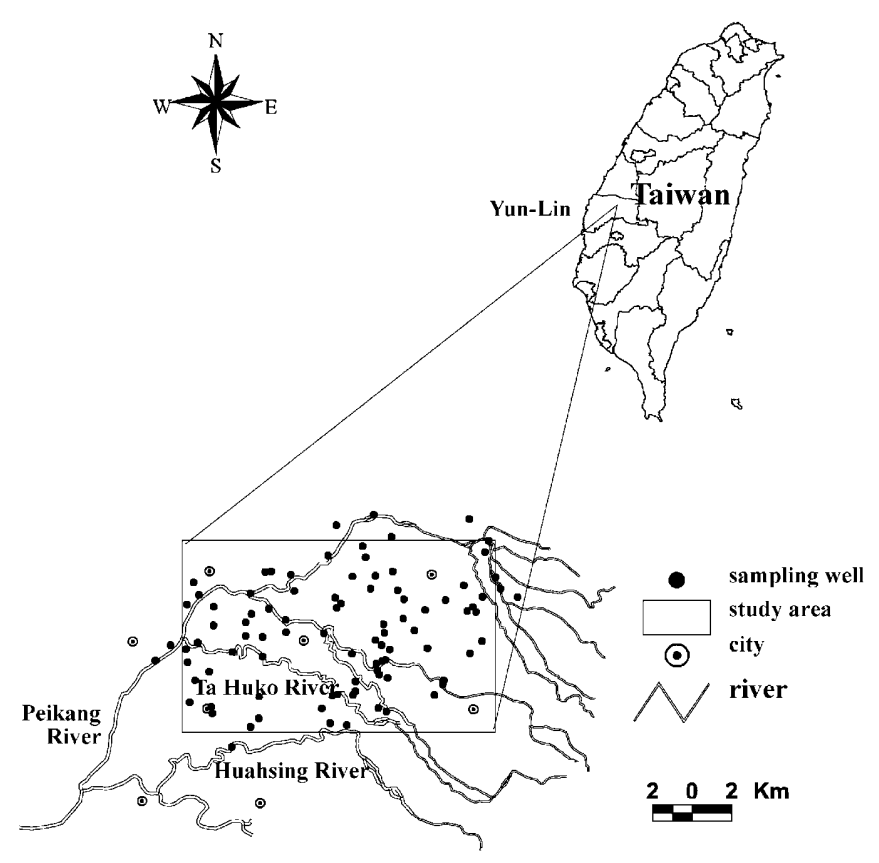

Fig. 1

The locations of sampling wells in the study area
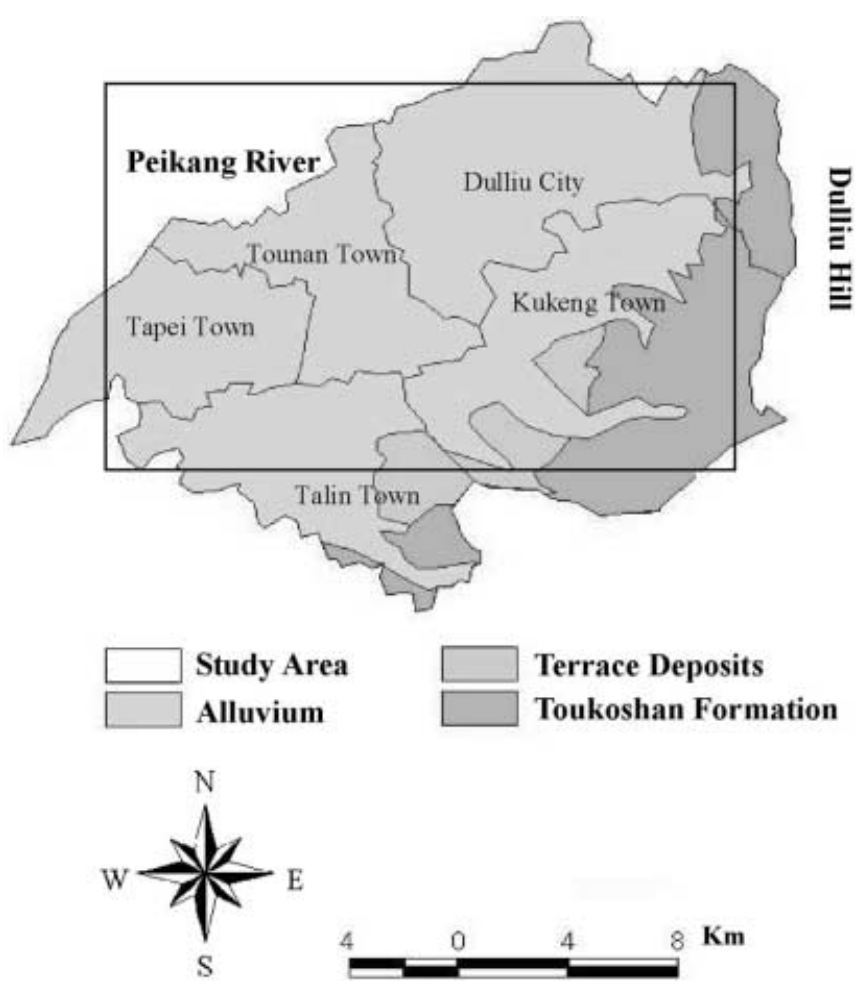

Fig. 2

The geological distribution in the study area

west and south-west, while increasing the thickness of the muddy and sandy stratum.

The well-drilling depth in Taipei County is the deepest in the country, with an average depth of $199.7 \mathrm{~m}$. Talin Town is second, with an average depth of $179.3 \mathrm{~m}$, 

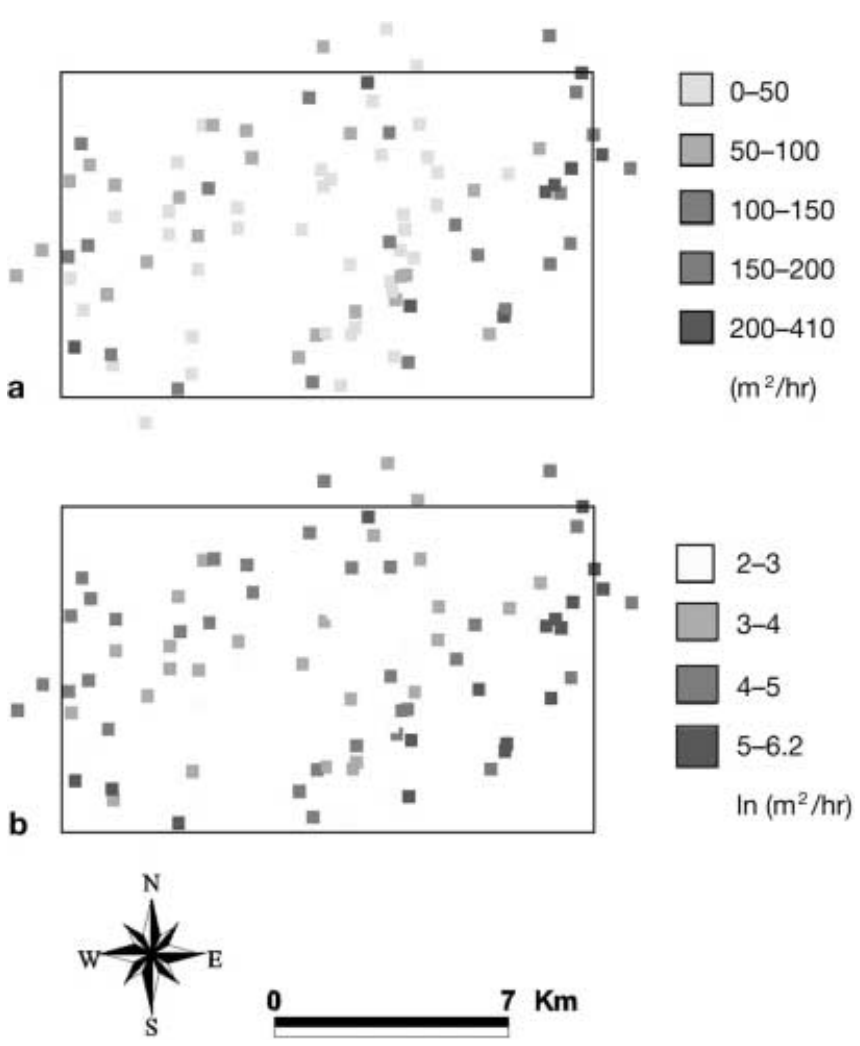

Fig. 3

The sampling points with a measured $\mathrm{T}$ (transmissivity); b $\ln (\mathrm{T})$

whereas Tounan and Kukeng are at 176.5 and $106.5 \mathrm{~m}$, respectively. The average thickness of the aquifer in the well-drilling depth range is $30.6-52.8 \mathrm{~m}$. The depth of the aquifer at the alluvia fan part of the Chuo-Shuei River and of the west bank of the Peikang River is $80 \mathrm{~m}$ at Huwei and an average of $100 \mathrm{~m}$ at Tuku and Yuanchang. The measured $\mathrm{T}$ (transmissivity) and $\ln (\mathrm{T})$ at the sampling points are displayed in Fig. 3. The basic descriptive statistics of the measured data are listed in Table 1. The coefficients of variance (CV) of $\mathrm{T}$ and $\ln (\mathrm{T})$ are 0.989 and 0.240 respectively. The histograms of the measured $\mathrm{T}$ and $\ln (\mathrm{T})$, performed by using statistical software (SPSS), are presented in Fig. 4. These results confirm that the measured transmissivity data display a skewed distribution and a wide range variation in space.

\section{Kriging}

Geostatistics (Journel and Hijbregts 1978; ASCE 1990a,b) is comprised of a collection of techniques for the analysis of spatially correlated data. Such techniques as kriging incorporate the spatial or temporal characteristics of actual data into statistical estimation processes. These techniques can be linear, such as point kriging, ordinary kriging and block kriging.

Geostatistics provide a variogram of data within a statistical framework, and includes spatial and temporal covariance functions. Unsurprisingly, these models are generally referred to as spatial or temporal structures, and are defined in terms of the correlation between any two points separated by either spatial or temporal distances. Kriging estimates are calculated as weighted sums of the adjacent sampled concentrations. These weights depend on the exhibited correlation structure. For instance, if data appear to be highly continuous in space, those points closer to the estimated points receive higher weights than those farther away. The criterion for the selection of these weights is a minimization of the estimation variance. In this framework, Kriging estimates may be regarded as the most accurate among all linear estimators (i.e. best linear unbiased estimator). Therefore, a kriging estimate can be thought of as simply an optimally weighted average of the surrounding sampled data given the variogram at an unsampled location (Cressie 1990).

\section{Sequential Gaussian simulation (SGS)}

Simulation is conducted upon the Gaussian transformation of the available measurements in the SGS process so that each simulated value is conditional on the original data and all previously simulated values (Deutsch and Journel 1992; Rouhani and others 1995). A simulated value at a visited point is randomly selected from the normal distribution function defined by the kriging mean and variance based on neighborhood values. Finally, the simulated normal values are transformed back into simulated values for the original variable. At a new randomly visited point, the simulated value is conditional on the original data and previously simulated values. This proc-

Table 1

Descriptive statistics of measured transmissivity

\begin{tabular}{|c|c|c|c|c|c|c|c|c|}
\hline & $\mathrm{n}$ & $\begin{array}{l}\text { Mean } \\
\left(\mathrm{m}^{2} / \mathrm{h}\right)\end{array}$ & $\begin{array}{l}\text { Median } \\
\left(\mathrm{m}^{2} / \mathrm{h}\right)\end{array}$ & $\begin{array}{l}\operatorname{Min} \\
\left(\mathrm{m}^{2} / \mathrm{h}\right)\end{array}$ & $\begin{array}{l}\operatorname{Max} \\
\left(\mathrm{m}^{2} / \mathrm{h}\right)\end{array}$ & $\begin{array}{l}\text { Std dev } \\
\left(\mathrm{m}^{2} / \mathrm{h}\right)\end{array}$ & Skewness & Kurtosis \\
\hline $\mathrm{T}$ & 92 & 93.088 & 64.275 & 8.637 & 407.483 & 92.082 & 1.872 & 3.352 \\
\hline $\ln (\mathrm{T})$ & 92 & $4.092 \ln$ & $4.163 \ln$ & $2.156 \ln$ & $6.010 \ln$ & 0.981 & -0.096 & -0.667 \\
\hline
\end{tabular}

$T$ Transmissivity 


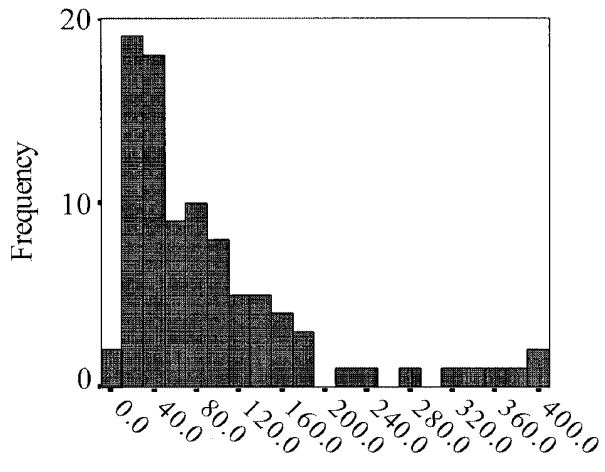

a

$\mathrm{T}\left(\mathrm{m}^{*} \mathrm{~m} / \mathrm{hr}\right)$

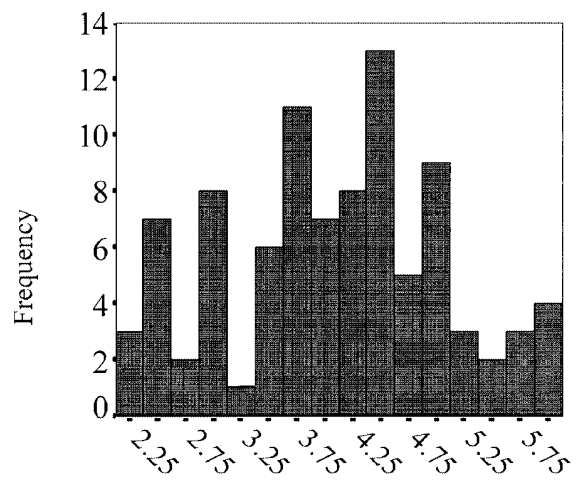

b

$\mathrm{LN}(\mathrm{T})\left(\ln \left(\mathrm{m}^{*} \mathrm{~m} / \mathrm{hr}\right)\right)$

Fig. 4

The histograms of investigated data a transmissivity $\mathrm{T} \mathbf{b}$ logarithm $\ln (\mathrm{T})$

ess is repeated until all points are simulated at each realization over the study area.

The NSCORE (normal score) program in the Geostatistical Software Library (GSLIB) (Deutsch and Journel 1992) is employed herein for fitting a normal variogram because it normalizes the investigated data. The variogram models of $\mathrm{T}$, normalized $\mathrm{T}$ and $\ln \mathrm{T}$ also fit within the GS + (Gamma Design 1995). Using SGSIM (sequential Gaussian simulation) and OKB2DM (ordinary kriging 2dimesion) programs in the GSLIB enables ordinary kriging, ln kriging and a SGS to be performed for soil transmissivity. These simulations and estimations are placed within a square ( 52 columns by 32 rows) grid consisting of $1664(0.3$ by $0.3 \mathrm{~km})$ cells. Five simulations are produced and the results are also transferred into an Arcview 3.0 (ESRI 1998) for display.

\section{Results and discussion}

\section{Variography}

Variograms are calculated for the data at an active lag of $2418 \mathrm{~m}$ and an active step of $0.17 \mathrm{~km}$ for the isotropic variography experiment. A least squares model to fit these variograms generated a relatively consistent set of best-fit models that have the lowest RSS (model reduced sum of squares) and highest $r^{2}$ values. Table 2 lists the parameters of the representative models. A Gaussian model with a nugget effect $=5630\left(\mathrm{~m}^{2} / \mathrm{h}\right)^{2}$, sill $=9120$ $\left(\mathrm{m}^{2} / \mathrm{h}\right)^{2}$ and range $=19.09 \mathrm{~km}$ has the best fit among the models (exponential or Gaussian) available in the software. The best fit variograms of the natural log and normalized investigated values are Gaussian model with a nugget effect $=0.75$, sill $=1.01$ and range $=6.00 \mathrm{~km}$, and a spherical model with a nugget effect $=0.65\left(\ln \left(\mathrm{m}^{2} / \mathrm{h}\right)^{2}\right)$, sill $=0.35\left(\ln \left(\mathrm{m}^{2} / \mathrm{h}\right)^{2}\right)$ and range $=5.13 \mathrm{~km}$ as depicted in Tables 3 and 4 . The variogram models with the high nugget effect illustrate a high small-scale variation or a measurement error.

Similarly, the anisotropic variography experimental variograms of measured $\mathrm{T}$, normalized $\mathrm{T}$ and $\ln (\mathrm{T})$ constructed in $0^{\circ}, 45^{\circ} 60^{\circ}$ and $90^{\circ}$ have a $22.5^{\circ}$ tolerance for the investigated transmissivity data. The best fit variograms of $T$ and $\ln (\mathrm{T})$ herein are a Gaussian model with a nugget effect $=6160.0\left(\mathrm{~m}^{2} / \mathrm{h}\right)^{2}$, sill $=4760.0\left(\mathrm{~m}^{2} / \mathrm{h}\right)^{2}$, minimum range $=17.24 \mathrm{~km}$ and maximum range $=17.24 \mathrm{~km}$, and a Gaussian model with a nugget effect $=0.76\left(\ln \left(\mathrm{m}^{2} /\right.\right.$ $\mathrm{h})^{2}$ ), sill $=0.20\left(\ln \left(\mathrm{m}^{2} / \mathrm{h}\right)^{2}\right)$, minimum range $=4.55 \mathrm{~km}$ and maximum range $=4.55 \mathrm{~km}$ as demonstrated in Tables 5 and 6 . The normalized variogram of these four examples with a $22.5^{\circ}$ tolerance is a Gaussian model with a nugget effect $=0.74$, sill $=0.24$, and minimum range $=4.30 \mathrm{~km}$ and maximum range $=4.30 \mathrm{~km}$ as displayed in Table 7. These variograms are isotropic because they have the same minimum and maximum value range. These spatial structure analyses also illustrate that the measured $\mathrm{T}$ data display an isotropic formation and a high nugget effect.

\section{Descriptive statistics}

The ordinary kriging estimates, ln kriging estimates and simulations are based on the above isotropic variogram models and 92 observations as summarized in Tables 8 and 9. The minimum value of kriging estimation is higher than the minimum value of measured $\mathrm{T}$ as demon-

Table 2

Variogram model of measured $\mathrm{T}$

\begin{tabular}{|c|c|c|c|c|c|}
\hline Model & $\begin{array}{l}\text { Nugget (C) } \\
\left(\mathrm{m}^{2} / \mathrm{h}\right)^{2}\end{array}$ & $\begin{array}{l}\text { Sill (S) } \\
\left(\mathrm{m}^{2} / \mathrm{h}\right)^{2}\end{array}$ & $\begin{array}{l}\text { Range (L) } \\
(\mathrm{km})\end{array}$ & RSS & $r^{2}$ \\
\hline Exponential $(\gamma=\mathrm{C}+\mathrm{S}[1-\exp (-\mathrm{h} / \mathrm{L})])$ & 3860.00 & 12790.00 & 12.46 & $2.28 \mathrm{E} 09$ & 0.268 \\
\hline Spherical $\left(\gamma=\mathrm{C}+\mathrm{S}\left[1.5(\mathrm{~h} / \mathrm{L})-0.5(\mathrm{~h} / \mathrm{L})^{3}\right]\right)$ & 4300.00 & 9610.00 & 20.14 & $2.25 \mathrm{E} 09$ & 0.278 \\
\hline Gaussian $\left(\gamma=\mathrm{C}+\mathrm{S}\left[1-\exp \left(-\mathrm{h}^{2} / \mathrm{L}^{2}\right)\right]\right)$ & 5630.00 & 9120.00 & 19.09 & $2.21 \mathrm{E} 09$ & 0.290 \\
\hline
\end{tabular}

Variogram; $h$ Distance between two points; RSS Model reduced sum of squares 
Table 3

Variogram model of $\ln (\mathrm{T})$

\begin{tabular}{|c|c|c|c|c|c|}
\hline Model & $\begin{array}{l}\text { Nugget }(\mathrm{C}) \\
\left(\operatorname{Ln}\left(\mathrm{m}^{2} / \mathrm{h}\right)\right)^{2}\end{array}$ & $\begin{array}{l}\text { Sill }(S) \\
\left(\operatorname{Ln}\left(\mathrm{m}^{2} / \mathrm{h}\right)\right)^{2}\end{array}$ & $\begin{array}{l}\text { Range (L) } \\
(\mathrm{km})\end{array}$ & RSS & $r^{2}$ \\
\hline Exponential $(\gamma=\mathrm{C}+\mathrm{S}[1-\exp (-\mathrm{h} / \mathrm{L})])$ & 0.70 & 1.03 & 3.15 & 0.0910 & 0.552 \\
\hline Spherical $\left(\gamma=\mathrm{C}+\mathrm{S}\left[1.5(\mathrm{~h} / \mathrm{L})-0.5(\mathrm{~h} / \mathrm{L})^{3}\right]\right)$ & 0.70 & 1.01 & 6.63 & 0.081 & 0.552 \\
\hline Gaussian $\left(\gamma=\mathrm{C}+\mathrm{S}\left[1-\exp \left(-\mathrm{h}^{2} / \mathrm{L}^{2}\right)\right]\right)$ & 0.75 & 1.01 & 6.00 & 0.077 & 0.573 \\
\hline
\end{tabular}

Variogram; $h$ Distance between two points; RSS Model reduced sum of squares

Table 4

Variogram model of normalized $\mathrm{T}$

\begin{tabular}{|c|c|c|c|c|c|}
\hline Model & $\begin{array}{l}\text { Nugget (C) } \\
\text { (dimensionless) }\end{array}$ & $\begin{array}{l}\text { Sill (S) } \\
\text { (dimensionless) }\end{array}$ & $\begin{array}{l}\text { Range (L) } \\
(\mathrm{km})\end{array}$ & RSS & $r^{2}$ \\
\hline Exponential $(\gamma=\mathrm{C}+\mathrm{S}[1-\exp (-\mathrm{h} / \mathrm{L})])$ & 0.61 & 0.39 & 1.68 & 8.184 & 0.054 \\
\hline Spherical $\left(\gamma=\mathrm{C}+\mathrm{S}\left[1.5(\mathrm{~h} / \mathrm{L})-0.5(\mathrm{~h} / \mathrm{L})^{3}\right]\right)$ & 0.65 & 0.35 & 5.13 & 8.060 & 0.069 \\
\hline Gaussian $\left(\gamma=\mathrm{C}+\mathrm{S}\left[1-\exp \left(-\mathrm{h}^{2} / \mathrm{L}^{2}\right)\right]\right)$ & 0.70 & 0.30 & 4.51 & 8.085 & 0.068 \\
\hline
\end{tabular}

Variogram; $h$ Distance between two points; RSS Model reduced sum of squares

Table 5

Anisotropic variogram models of measured $\mathrm{T}$

\begin{tabular}{|c|c|c|c|c|c|c|}
\hline Model & $\begin{array}{l}\text { Nugget effect }(\mathrm{C}) \\
\left(\mathrm{m}^{2} / \mathrm{h}\right)^{2}\end{array}$ & $\begin{array}{l}\text { Sill (S) } \\
\left(\mathrm{m}^{2} / \mathrm{h}\right)^{2}\end{array}$ & $\begin{array}{l}\text { Max range }\left(\mathrm{L}_{1}\right) \\
(\mathrm{km})\end{array}$ & $\begin{array}{l}\text { Min range }\left(\mathrm{L}_{2}\right) \\
(\mathrm{km})\end{array}$ & RSS & $r^{2}$ \\
\hline Exponential $\left(\gamma=\mathrm{C}+\mathrm{S}\left[1-\exp \left(-\mathrm{h}^{\prime} / \mathrm{L}_{2}\right)\right]\right)$ & 4970.00 & 6520.00 & 9.39 & 9.39 & $8.50 \mathrm{E} 8$ & 0.187 \\
\hline Spherical $\left(\gamma=\mathrm{C}+\mathrm{S}\left[1.5\left(\mathrm{~h}^{\prime} / \mathrm{L}_{2}\right)-0.5\left(\mathrm{~h}^{\prime} / \mathrm{L}_{2}\right)^{3}\right]\right)$ & 5490.00 & 5340.00 & 20.00 & 20.00 & $8.41 \mathrm{E} 8$ & 0.199 \\
\hline Gaussian $\left(\gamma=\mathrm{C}+\mathrm{S}\left[1-\exp \left(-\mathrm{h}^{\prime 2} / \mathrm{L}_{2}^{2}\right)\right]\right)$ & 6160.00 & 4760.00 & 17.24 & 17.24 & $8.76 \mathrm{E} 8$ & 0.208 \\
\hline
\end{tabular}

Variogram, h: distance between two points, $h^{\prime}=\frac{\mathrm{L}_{2}}{\mathrm{~L}_{1}} \mathrm{~h}$

RSS Model reduced sum of squares

strated in Table 8. In contrast, the maximum value of kriging estimation is significantly lower than that of measured T. These results illustrate that kriging tends to smooth out extreme values of the investigated data set. Moreover, the skewness and kurtosis of kriging estimates are also lower than those of measured T. Thus, kriging cannot produce the proper distribution for the investigated data.

The mean, median, variance, kurtosis and skewness of the simulations are extremely close to those of the investigated data shown in Table 8. The CV of ordinary kriging estimates is 0.459 , whereas the CVs of simulations (Sim 1, 2, 3, 4 and 5) are 0.983, 0.989, 0.955, 0.977 and 1.011. The above results indicate that the ordinary kriging process may not preserve the variability of the investigated process. Moreover, this minimization of the prediction error variance involves smoothing the actual variability. Nevertheless, SGS can reproduce the statistics for the investigated transmissivity.

The simulations are transformed into a natural log format to compare the results of ln kriging and SGS. The mean, median, standard deviation, kurtosis and skewness of the simulations are extremely close to those of the in- vestigated data as displayed in Table 9. The standard deviation of ln kriging estimation is significantly lower than the standard deviation of $\ln (\mathrm{T})$ as presented in Table 9. The CV value of ln ordinary kriging is 0.119 , whereas the CV values of simulations $1,2,3,4$ and 5 in natural log formation are $0.236,0.239,0.229,0.234$ and 0.246 , which are very close to that $(0.240)$ of the investigated data. Similarly, the natural log kriging results display the smoothing effect and low variation on the estimated values as presented in Table 9. The natural log ordinary kriging process may not preserve the variability of the investigated natural log process. The SGS performs multiple realizations that obtain statistics similar to the investigated data, as demonstrated in Table 9.

The histograms of simulations and estimations are also rendered by statistical software (SPSS). Comparing the histograms (Figs. 4-6) reveals that the histograms of the simulated realities more closely fit the histogram of the investigated data than that of ordinary kriging estimates, and even natural $\log$ kriging estimates. Figures 4-6 reveal that both the upper and lower tails of the distribution are well produced by simulation. 
Table 6

Anisotropic variogram models of $\ln (\mathrm{T})$

\begin{tabular}{|c|c|c|c|c|c|c|}
\hline Model & $\begin{array}{l}\text { Nugget effect } \\
\left(\operatorname{Ln}\left(\mathrm{m}^{2} / \mathrm{h}\right)\right)^{2}\end{array}$ & $\begin{array}{l}\text { Sill } \\
\left(\operatorname{Ln}\left(\mathrm{m}^{2} / \mathrm{h}\right)\right)^{2}\end{array}$ & $\begin{array}{l}\text { Max range } \\
\left(\mathrm{L}_{1}\right)(\mathrm{km})\end{array}$ & $\begin{array}{l}\text { Min range } \\
\left(\mathrm{L}_{2}\right)(\mathrm{km})\end{array}$ & RSS & $r^{2}$ \\
\hline Exponential $\left(\gamma=\mathrm{C}+\mathrm{S}\left[1-\exp \left(-\mathrm{h}^{\prime} / \mathrm{L}_{2}\right)\right]\right)$ & 0.67 & 0.28 & 1.31 & 1.31 & 67.10 & 0.036 \\
\hline Gaussian $\left(\gamma=\mathrm{C}+\mathrm{S}\left[1-\exp \left(-\mathrm{h}^{\prime 2} / \mathrm{L}_{2}^{2}\right)\right]\right)$ & 0.76 & 0.20 & 4.55 & 4.55 & 66.84 & 0.039 \\
\hline
\end{tabular}

Variogram, h: distance between two points, h' $=\frac{\mathrm{L}_{2}}{\mathrm{~L}_{1}} \mathrm{~h}$

RSS Model reduced sum of squares

Table 7

Anisotropic variogram models of normalized $\mathrm{T}$

\begin{tabular}{|c|c|c|c|c|c|c|}
\hline Model & $\begin{array}{l}\text { Nugget } \\
\text { (dimensionless) }\end{array}$ & $\begin{array}{l}\text { Sill } \\
\text { (dimensionless) }\end{array}$ & $\begin{array}{l}\text { Max range } \\
\left(\mathrm{L}_{1}\right)(\mathrm{km})\end{array}$ & $\begin{array}{l}\text { Min range } \\
\left(\mathrm{L}_{2}\right)(\mathrm{km})\end{array}$ & RSS & $r^{2}$ \\
\hline Exponential $\left(\gamma=\mathrm{C}+\mathrm{S}\left[1-\exp \left(-\mathrm{h}^{\prime} / \mathrm{L}_{2}\right)\right]\right)$ & 0.65 & 0.33 & 1.48 & 1.48 & 72.46 & 0.036 \\
\hline Gaussian $\left(\gamma=\mathrm{C}+\mathrm{S}\left[1-\exp \left(-\mathrm{h}^{\prime 2} / \mathrm{L}_{2}^{2}\right)\right]\right)$ & 0.74 & 0.24 & 4.30 & 4.30 & 72.15 & 0.037 \\
\hline
\end{tabular}

Variogram, h: distance between two points, $h^{\prime}=\frac{\mathrm{L}_{2}}{\mathrm{~L}_{1}} \mathrm{~h}$

RSS Model reduced sum of squares

Table 8

Descriptive statistics of kriging estimates and simulations

\begin{tabular}{|c|c|c|c|c|c|c|c|c|}
\hline & $\mathrm{n}$ & $\begin{array}{l}\text { Mean } \\
\left(\mathrm{m}^{2} / \mathrm{h}\right)\end{array}$ & $\begin{array}{l}\text { Median } \\
\left(\mathrm{m}^{2} / \mathrm{h}\right)\end{array}$ & $\begin{array}{l}\operatorname{Min} \\
\left(\mathrm{m}^{2} / \mathrm{h}\right)\end{array}$ & $\begin{array}{l}\operatorname{Max} \\
\left(\mathrm{m}^{2} / \mathrm{h}\right)\end{array}$ & $\begin{array}{l}\text { Std dev } \\
\left(\mathrm{m}^{2} / \mathrm{h}\right)\end{array}$ & Skewness & Kurtosis \\
\hline $\mathrm{T}$ & 92 & 93.088 & 64.275 & 8.637 & 407.483 & 92.082 & 1.872 & 3.352 \\
\hline Ok & 1664 & 87.066 & 73.366 & 33.783 & 196.713 & 39.848 & 1.211 & 0.330 \\
\hline $\operatorname{Sim}(1)$ & 1664 & 90.203 & 61.611 & 8.709 & 407.971 & 88.642 & 1.915 & 3.557 \\
\hline $\operatorname{Sim}(2)$ & 1664 & 91.790 & 63.849 & 8.650 & 407.980 & 90.753 & 1.865 & 3.222 \\
\hline $\operatorname{Sim}(3)$ & 1664 & 99.109 & 72.950 & 8.697 & 407.859 & 94.618 & 1.761 & 2.695 \\
\hline $\operatorname{Sim}(4)$ & 1664 & 91.165 & 64.274 & 8.642 & 407.920 & 89.028 & 1.908 & 3.469 \\
\hline $\operatorname{Sim}(5)$ & 1664 & 86.736 & 59.406 & 8.649 & 407.690 & 87.643 & 1.917 & 3.494 \\
\hline
\end{tabular}

$T$ Transmissivity; Ok Ordinary kriging; Sim Simulation

Table 9

Descriptive statistics of $\ln$ kriging estimates and simulations

\begin{tabular}{|c|c|c|c|c|c|c|c|c|}
\hline & $\mathrm{n}$ & $\begin{array}{l}\text { Mean ln } \\
\left(\mathrm{m}^{2} / \mathrm{h}\right)\end{array}$ & $\begin{array}{l}\text { Median ln } \\
\left(\mathrm{m}^{2} / \mathrm{h}\right)\end{array}$ & $\begin{array}{l}\text { Min ln } \\
\left(\mathrm{m}^{2} / \mathrm{h}\right)\end{array}$ & $\begin{array}{l}\operatorname{Max} \ln \\
\left(\mathrm{m}^{2} / \mathrm{h}\right)\end{array}$ & $\begin{array}{l}\text { Std dev. ln } \\
\left(\mathrm{m}^{2} / \mathrm{h}\right)\end{array}$ & Skewness & Kurtosis \\
\hline $\operatorname{Ln}(\mathrm{T})$ & 92 & 4.092 & 4.163 & 2.156 & 6.010 & 0.981 & -0.096 & -0.667 \\
\hline $\operatorname{Sim}(1)$ & 1664 & 4.071 & 4.121 & 2.164 & 6.011 & 0.961 & -0.082 & -0.659 \\
\hline $\operatorname{Sim}(2)$ & 1664 & 4.077 & 4.157 & 2.158 & 6.011 & 0.975 & -0.078 & -0.713 \\
\hline $\operatorname{Sim}(3)$ & 1664 & 4.174 & 4.290 & 2.163 & 6.011 & 0.957 & -0.135 & -0.642 \\
\hline
\end{tabular}

Ln Transmissivity; lnOk Natural log of ordinary kriging; Sim Simulation 


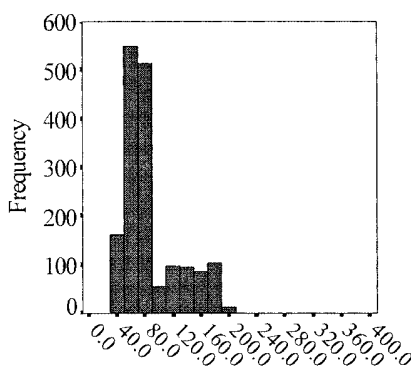

a
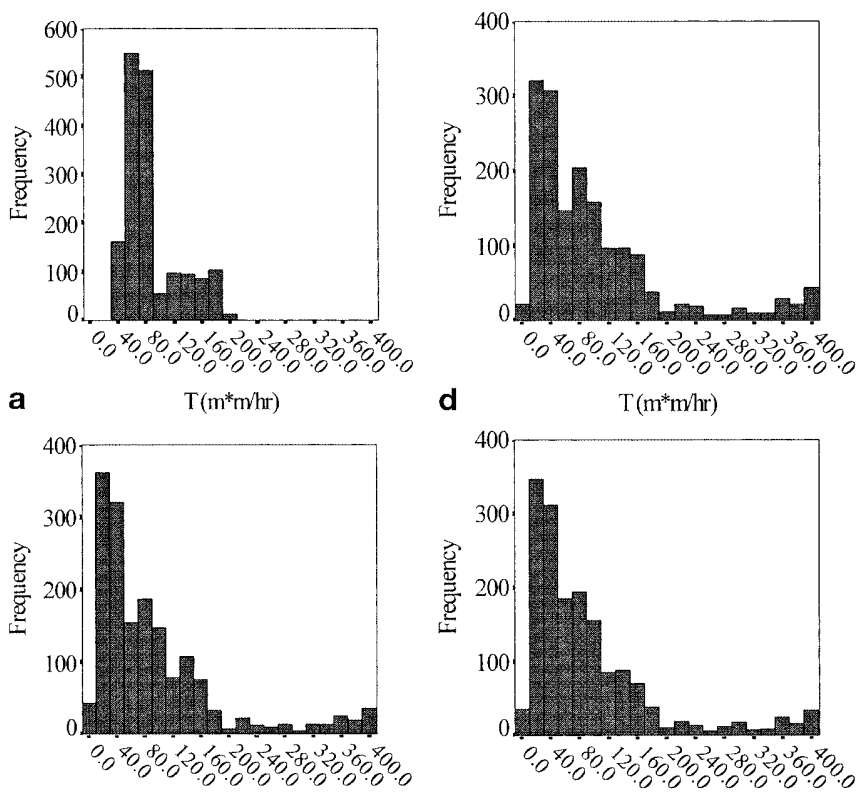

b

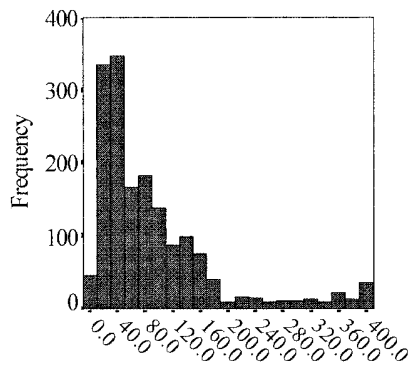

c

$$
\mathrm{T}\left(\mathrm{m}^{*} \mathrm{~m} / \mathrm{hr}\right)
$$

$$
\text { d }
$$
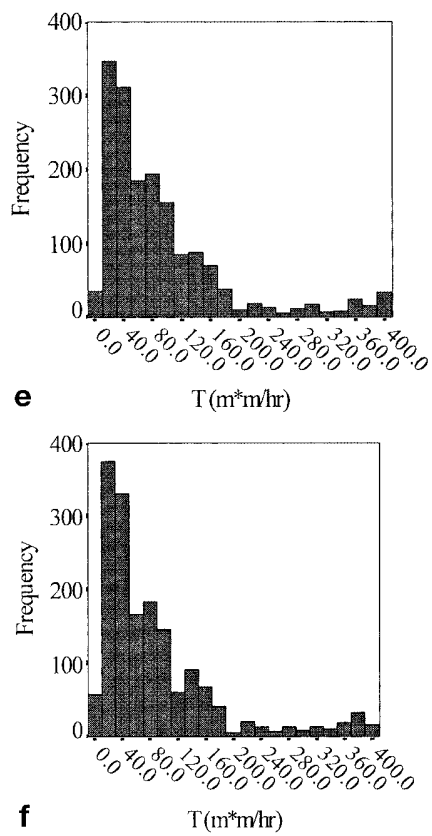

Fig. 5

The histograms of kriging estimate and simulations: a Kriging; b Simulation 1; c Simulation 2; d Simulation 3; e Simulation 4; f Simulation 5

\section{Experimental variogram}

The experimental variograms of the measured, estimated and simulated values are also performed with the same lag interval as displayed in Fig. 7. These experimental variograms indicate that the ordinary kriging values display a well-structured variogram with a low spatial variability, but cannot perform the spatial structure and smallscale variation for the investigated values as presented in Fig. 7a. The experimental variograms of all simulations tend to fit the experimental variogram of the investigated data according to Fig. 7a. These experimental variograms illustrate that a SGS can perform very well in terms of reproducing the spatial structure (experimental variogram) for the investigated values, whereas ordinary kriging does not perform well.

The experimental variograms of natural log simulations also closely fit the spatial structure for the natural log of investigated values as displayed in Fig. 7b. The natural log ordinary kriging estimates also display a well-structured variogram with a low spatial variability, but cannot perform the small-scale variation for the investigated val-
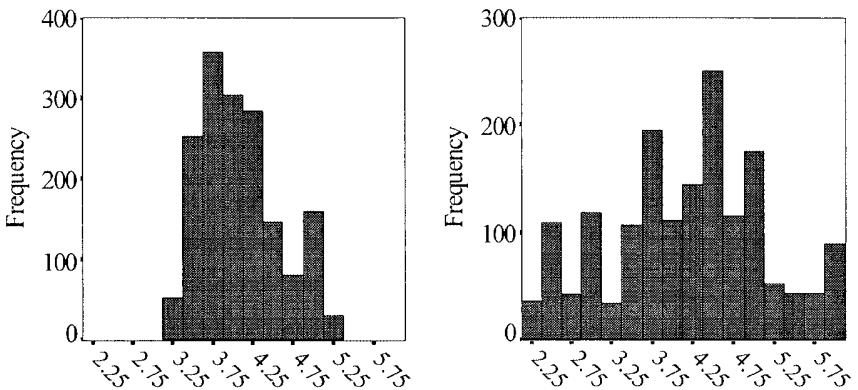

a

$\operatorname{LN}(\mathrm{T})\left(\ln \left(\mathrm{m}^{*} \mathrm{~m} / \mathrm{hr}\right)\right)$

d

$\operatorname{LN}(\mathrm{T})\left(\ln \left(\mathrm{m}^{*} \mathrm{~m} / \mathrm{hr}\right)\right)$

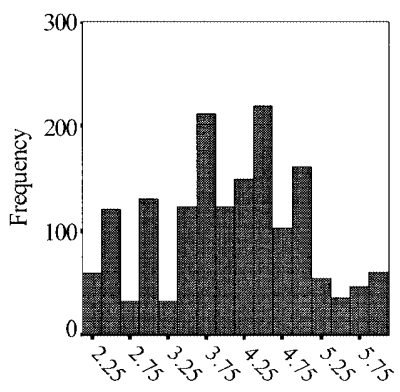

b

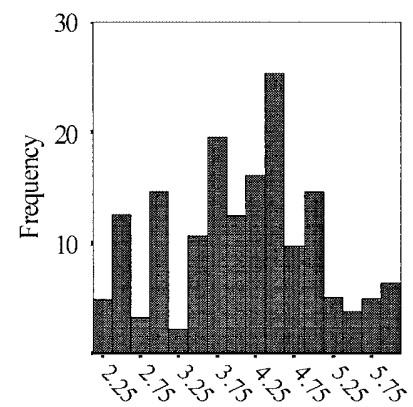

e

LN(T) $\left(\ln \left(\mathrm{m}^{*} \mathrm{~m} / \mathrm{r}\right)\right)$
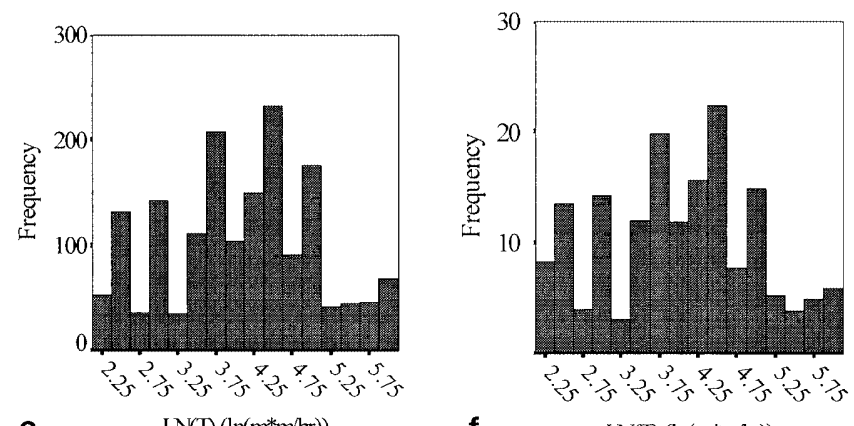

$\mathbf{f}$

LN(T) $\left(\ln \left(m^{*} m m^{2}\right)\right)$

Fig. 6

The histograms of natural log format of kriging estimate and simulations: a ln kriging; b Simulation 1; c Simulation 2; d Simulation 3; e Simulation 4; f Simulation 5

ues as demonstrated in Fig. 7b. These results are an improvement of the above descriptive statistic results, indicating that the simulation can reproduce the statistics of the investigated data.

\section{Spatial distribution}

Ordinary kriging and a SGS for transmissivity in the study area are also performed and mapped in GIS. The map of ordinary kriging estimates reveal that kriging tends to smooth out extreme values of the investigated data set as displayed in Fig. 8a. The simulation maps in Figs. 8 and 9 illustrate that the large- and small-scale continuity patterns produced by the SGS are visually similar to those in the investigated data map. Subjectively comparing Figs. 3a and 8a reveals that the kriging results may overestimate areas with high transmissivity, and underestimate areas with extremely high transmissivity. The conditional simulated maps of $\mathrm{T}$ are rather irregular, and 


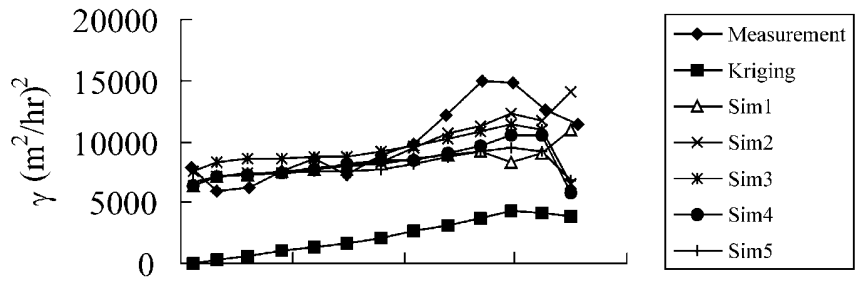

a

$\begin{array}{lllll}0 & 5 & 10 & 15 & 20\end{array}$

$\operatorname{Lag}(\mathrm{km})$

b

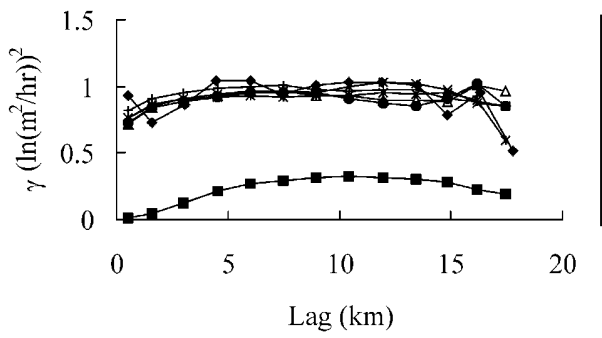

Fig. 7

The experimental variograms of measured, estimated and simulated values in a $\mathrm{T}$ (transmissivity); $\mathbf{b} \ln (\mathrm{T})$
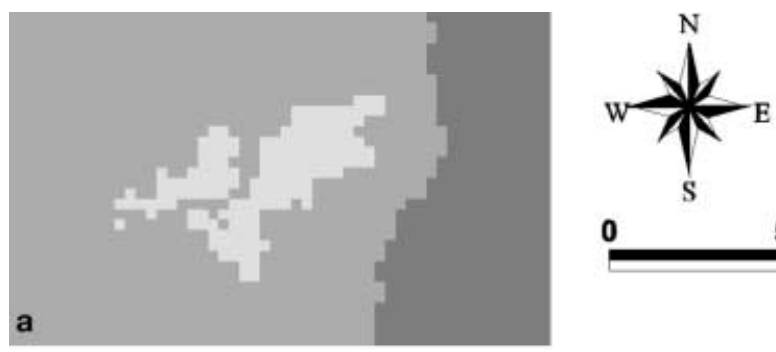

$5 \mathrm{Km}$
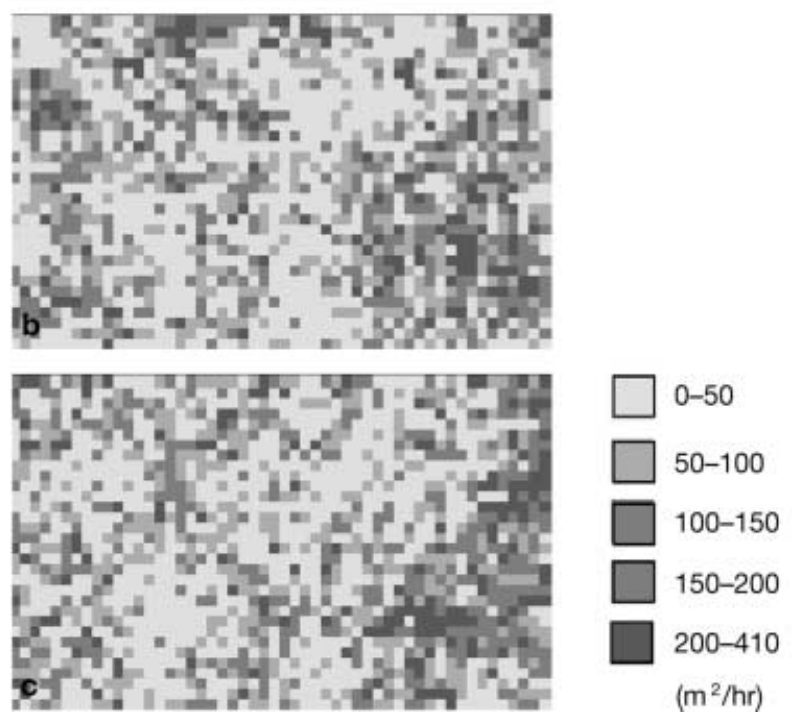

Fig. 8

The spatial maps of transmissivity of: a Kriging; b Simulation 1; c Simulation 2
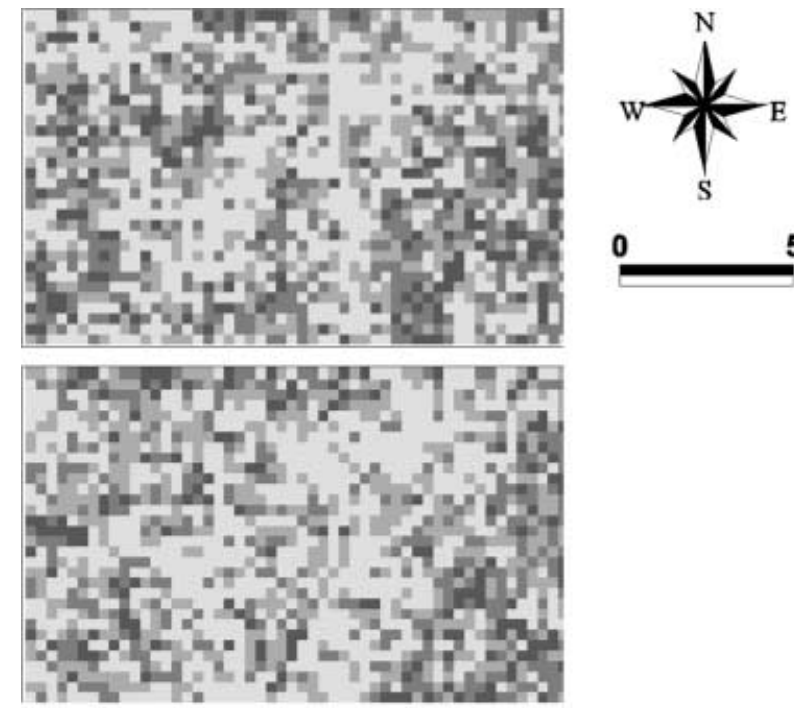

0

$5 \mathrm{Km}$

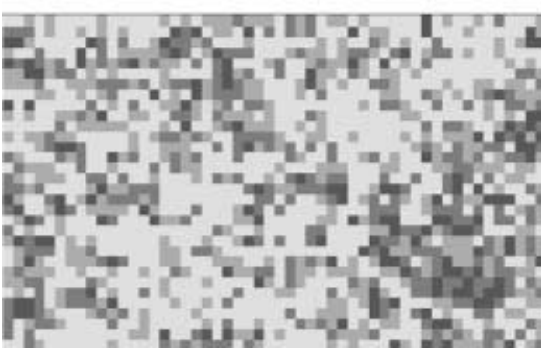

$0-50$

50-100

$100-150$

$150-200$

$200-410$

$\left(\mathrm{m}^{2} / \mathrm{hr}\right)$

Fig. 9

The spatial maps of transmissivity of: a Simulation 3; b Simulation 4; c Simulation 5

sites with high transmissivity values in all simulations may have a low value at neighboring points as shown in Figs. 7, 8 and 9. These maps also illustrate that kriging estimates are significantly smoother than those of any of the simulations. Although kriging provides the optimal estimation of transmissivity at unsampled sites, it cannot reproduce the spatial variability for the investigated data in this case study. However, a SGS can reproduce the spatial variation for the investigated data. Moreover, each realization of the simulations provides a measure of spatial uncertainty over this study area.

The ln ordinary kriging results also overestimate areas with high $\ln \mathrm{T}$, and underestimate areas with very high $\ln \mathrm{T}$, as shown in Figs. $3 \mathrm{~b}$ and 10a. The natural log transformed simulations mapped in Tables. 10 and 11 are also rather irregular because a high transmissivity area in simulations may have low transmissivity at neighbor sites, as displayed in Table 11. These maps also illustrate that natural log kriging estimates are markedly smoother than the simulations' estimates.

\section{Summary}

The spatial structure analyses in this study reveal that the measured transmissivity data display isotropic formations and high nugget effects at the Dulliu area in Yun-Lin County, Taiwan. The variogram models with a high nugget effect of investigated transmissivity data illustrate a 

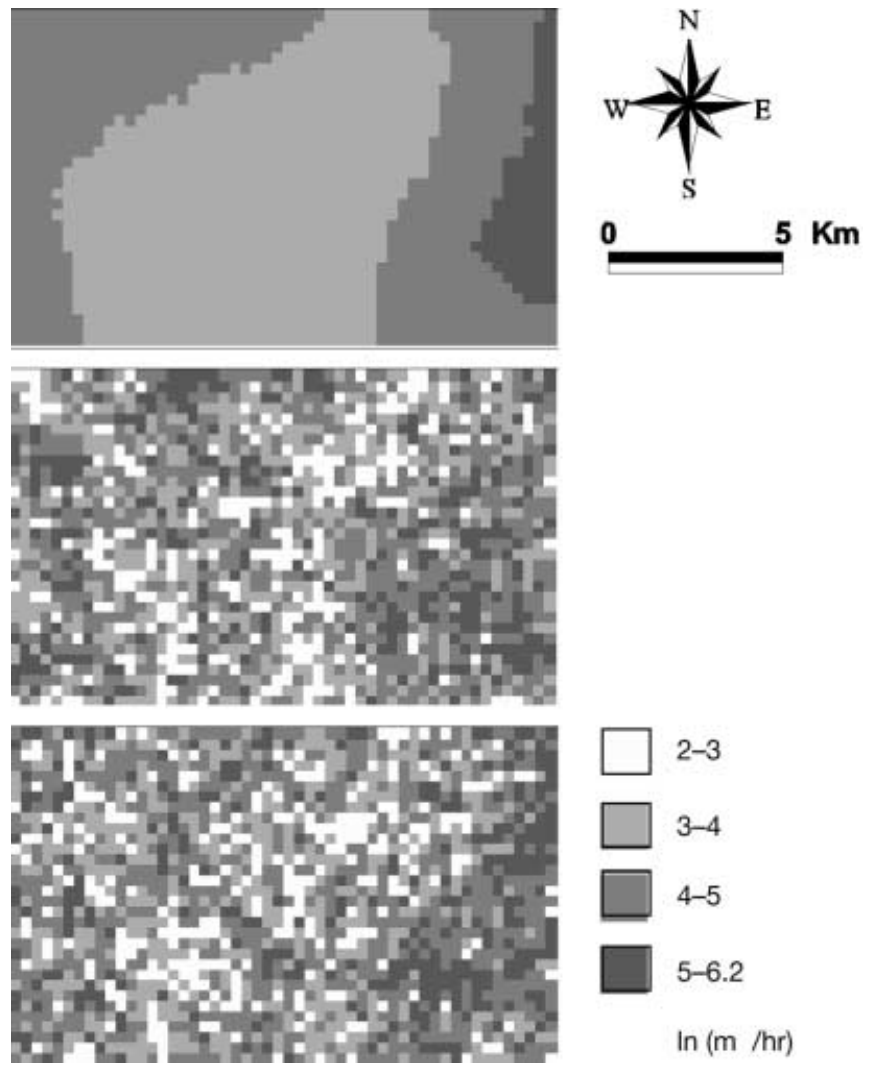

Fig. 10

The spatial maps of $\ln \mathrm{T}$ of: a ln kriging; $\mathbf{b}$ Simulation 1; c Simulation 2

high small-scale variation. Although Kriging provides the optimal estimation of $\mathrm{T}$ at unsampled sites, the estimated values based on ordinary kriging and natural log kriging display lower variations than the actual investigated transmissivity data. These two techniques fail to reproduce the measured extreme $T$ and $\ln (\mathrm{T})$ values. A SGS can reproduce both the extreme measured transmissivity and overall transmissivity spatial distribution. SGS with multiple realizations has significant advantages at a site with high variation in investigated data compared with ordinary and natural log kriging techniques. These alternative realizations of transmissivity can also be the input data of groundwater flow models. Thus, these three techniques may be effective in assessing the uncertainty of investigated data and a SGS can also be applied to assess stochastic elements in a complex transmissivity study.
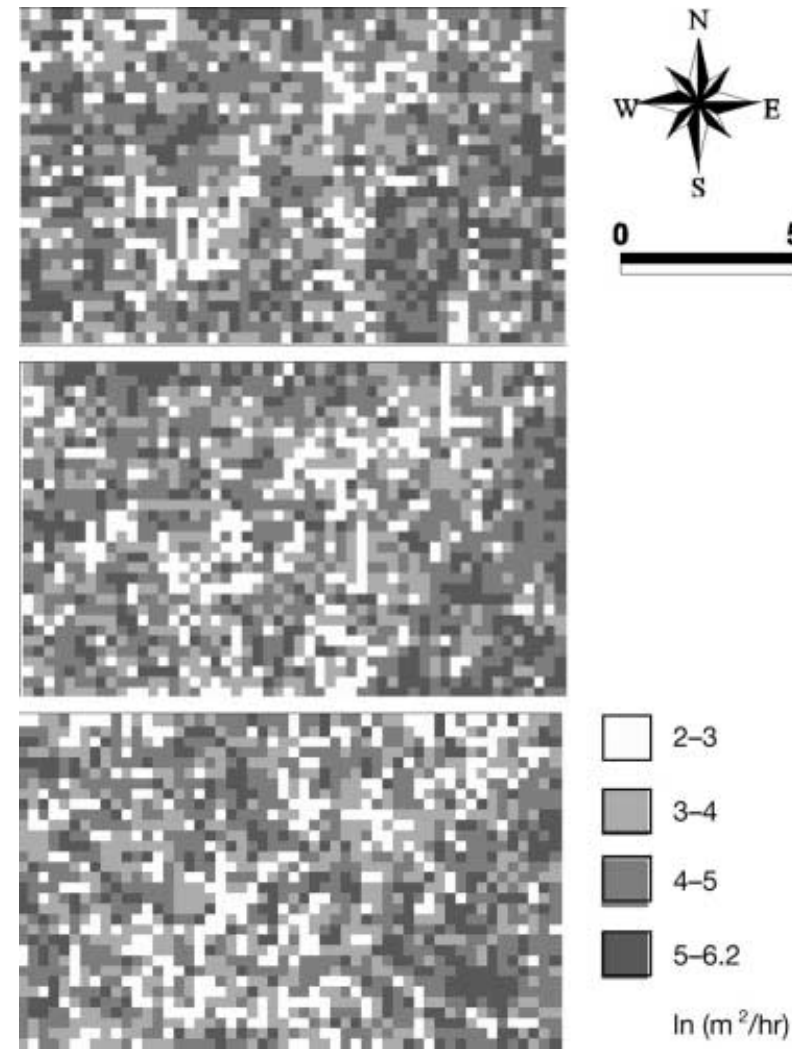

Fig. 11

The spatial maps of $\ln T$ of a Simulation 3; b Simulation 4; c Simulation 5

\section{References}

Andersson J, Shapiro AM (1983) Stochastic analysis of onedimensional steady state unsaturated flow: a comparison of Monte Carlo and perturbation methods. Water Resources Res 19:121-133

ASCE (American Society of Civil Engineers) Task Committee on geostatistical techniques in geohydrology (S. Rouhani, Chairman and Principle Author) (1990a) Review of geostatistics in geohydrology, I. Basic concepts. ASCE J Hydraul Engineer 116:612-632

ASCE (American Society of Civil Engineers) Task Committee on geostatistical techniques in geohydrology (S. Rouhani, Chairman and Principle Author) (1990b) Review of geostatistics in geohydrology, II Applications. ASCE J Hydraul Engineer 116:633-658

Bark AA, Gelhar LW, Gutjahr AL, MacMillan JR (1978) Stochastic analysis of spatial variability in subsurface flows, 1 . Comparison of one-and-three dimensional flows. Water Resources Res 14:263-271

Bjerg PL, Hinsby K, Christensen TH, Gravesen P (1992) Spatial variability of hydraulic of an unconfined sandy aquifer determined by a mini slug test. J Hydrol 136:107-122

Chirlin GR, Dagan G (1980) Theoretical head variogram for steady flow in statistically homogeneous aquifers. Water Resources Res 16:1001-1015

Christakos G (1992) Random field models in earth sciences. Academic Press, New York 
Christensin S (1997) On the strategy of estimating regionalscale transmissivity fields. Groundwater 35:131-139

Clifton PM, Neuman SP (1982) Effects of kriging and inverse modeling on conditional simulation of the Avra Valley aquifer in southern Arizona. Water Resources Res 18:1234-1251

Cressie C (1990) The origins of kriging. Math Geol 22:239-252

DeLhomme JP (1979) Spatial variability and uncertainty in groundwater flow parameters: a geostatistical approach. Water Resources Res 15:269-280

Deutsch C, Journel AG (1992) GSLIB, Geostatistical software library and user's guide. Oxford University Press, New York

Difederico V, Neuman SP (1997) Scaling of random-fields by means of truncated power variograms and associated spectra. Water Resources Res 33:1075-1085

Dowd PA (1982) Lognormal kriging-the general case. Math Geol 14:474-500

Eggleston JR, Rojstaczer SA, Peirce JJ (1996) Identification of hydraulic conductivity structure in sand and gravel aquifers: Cape Cod Data Set. Water Resources Res 32:1209-1222

ESRI (Environmental Systems Research Institute) (1998) Arcview GIS, ESRI, Redlands, CA

FABBRI, P (1997) Transmissivity in the geothermal euganean basin: a geostatistical analysis. Groundwater 35:881-887

FreEze RA (1975) A stochastic-conceptual analysis of one-dimension groundwater flow in nonuniform homogeneous media. Water Resources Res 11:725-741

Gamma Design Software (1995) GS + :geostatistics for the environmental sciences. Version 2.3. Gamma Design Software, Plainwell, MI

Hoeksema RJ, Kitanidis PK (1985) Analysis of spatial structure of properties of selected aquifers. Water Resources Res $21: 563-572$

JouRnel AG (1980) The lognormal approach to predicting local distributions of selective mining unit grades. Math Geol $12: 285-301$

Journel AG, Huijbregts CJ (1978) Mining: geostatistics. Academic Press, New York
Kentwell DJ, Вloom LM, Comber GA (1999) Improvements in grade tonnage curve prediction via sequential Gaussian fractal simulation. Math Geol 31:311-325

Mowrer HT (1997) Propagating uncertainty through spatial estimation processes for old-growth subalpine forests using sequential Gaussian simulation in GIS. Ecolog Modelling 98:73-86

Neuman SP, Winter CL, Newman CM (1987) Stochastic theory of field-scale fickian dispersion in anisotropic porous media. Water Resource Res 23:453-466

RENDU JM (1979) Normal and lognormal estimation. Math Geol $11: 407-422$

Rivoirard J (1990) A review of lognormal estimators for in situ reserves. Math Geol 22:213-221

Rотн C (1998) Is lognormal kriging suitable for local estimation? Math Geol 30:999-1009

Rouhani S, Lin YP, SHI Y (1995) H-area/ITP geostatistical assessment in-situ and engineering properties, final technical report. Westinghouse Savannah River Company, Aiken, SC

RubIN Y (1990) Stochastic modeling of microdispersion in heterogeneous porous media. Water Resources Res 26:133-141

SALANDin P, Fiorotto V (1998) Solute transport in highly heterogeneous aquifers. Water Resources Res 34:949-961

Smith L (1981) Spatial variability of flow parameters in a stratified sand. Math Geol 13:1-21

Smith L, Freeze RA (1979) Stochastic analysis of steady state groundwater flow in a bounded domain, 1. One-dimensional simulations. Water Resources Res 15:521-528

Sterk G, Stein A (1997) Mapping wind-blown mass transport by modeling variability in space and time. Soil Sci Soc Am J $61: 232-239$

VARLJEN MD, SHAFER JM (1991) Assessment of uncertainty in timerelated capture zones using conditional simulation of hydraulic conductivity. Groundwater 29:737-748 